\title{
DESIGN ALGORITHM FOR THE DEVELOPMENT OF A TECHNOLOGICAL SYSTEM APPLYING PAINT AND VARNISH COATINGS FOR LOW-TONNAGE CHEMICALS
}

\author{
1Veniamin BOLDYREV, ${ }^{2}$ rina SHARAPOVA, ${ }^{2,3}$ Vladimir MEN'SHIKOV, 'Boris BOGOMOLOV, \\ ${ }^{2}$ Anastasiya SAVINA, ${ }^{1,2}$ Nikita BOGATOV, ${ }^{3}$ Sergey KUZNETSOV \\ 1Bauman Moscow State Technical University, Moscow, Russia, boldyrev.v.s@bmstu.ru \\ ${ }^{2}$ D. Mendeleev State Technical University, Moscow, Russia \\ ${ }^{3}$ Scientific Production Association «Lakokraspokrytiye», Khotkovo, Moscow region, Russia, mail@npolkp.ru
}

https://doi.org/10.37904/metal.2021.4166

\begin{abstract}
The article provides an analysis and basic approaches to the choice of paint and varnish coatings and the technology of their application. A logical model of the life cycle of a paintwork system is presented. The key features of the development of an algorithm for designing a technological line for applying paint and varnish coatings are considered, with the possibility of choosing a coating system taking into account the operational, technological and economic characteristics of the project. The algorithm developed by the authors was tested during the implementation of a project for the development and implementation of a paint-and-lacquer coating system to protect metal structures operated in cold (temperature ranges from $-60^{\circ} \mathrm{C}$ to $+40^{\circ} \mathrm{C}$ ) and arctic climates.
\end{abstract}

Keywords: Paint and varnish coatings, paint technologies, corrosion protection, technological line design, business process

\section{INTRODUCTION}

The corrosion process causes colossal damage to metal surfaces used in an aggressive environment. Currently, $40-50 \%$ of metal structures are used in aggressive environments, $30 \%$ in slightly aggressive environments and only $10 \%$ do not require corrosion protection. The most common and effective method of anti-corrosion protection of metals is paint and varnish coatings, this is due to the durability and aesthetic appearance of the painted surface. Paints and varnishes are one of the most important products of the chemical industry, as they are in high demand on the market, therefore they have more opportunities for the implementation of scientific and technical innovative technologies (paint technologies) [1].

The most relevant are the directions for the introduction of innovative technologies in the field of paints and varnishes and paints and varnishes, based on the development of environmentally friendly paints and varnishes and energy-saving paint and varnish coatings for anticorrosive protection of metal structures.

To create modern resource-saving, environmentally friendly technological processes of painting, various standards are used (GOST 9.104 "Paint coatings. Operating conditions group", GOST 9.032 "Paint coatings. Groups, technical requirements and designations"), but the most reliable way to assess the required characteristics is used GOST 9.401 "Paint and varnish coatings. General requirements and methods of accelerated tests for resistance to climatic factors" [2]. GOST is the fundamental standard for the selection of paint and varnish systems for various types of metal products and their operating conditions. The choice of paintwork system depends on the operating conditions in accordance with GOST 9.401 [3,4]. The logical model for the choice of paint and varnish coatings involved in the design process is presented in Figure 1. 


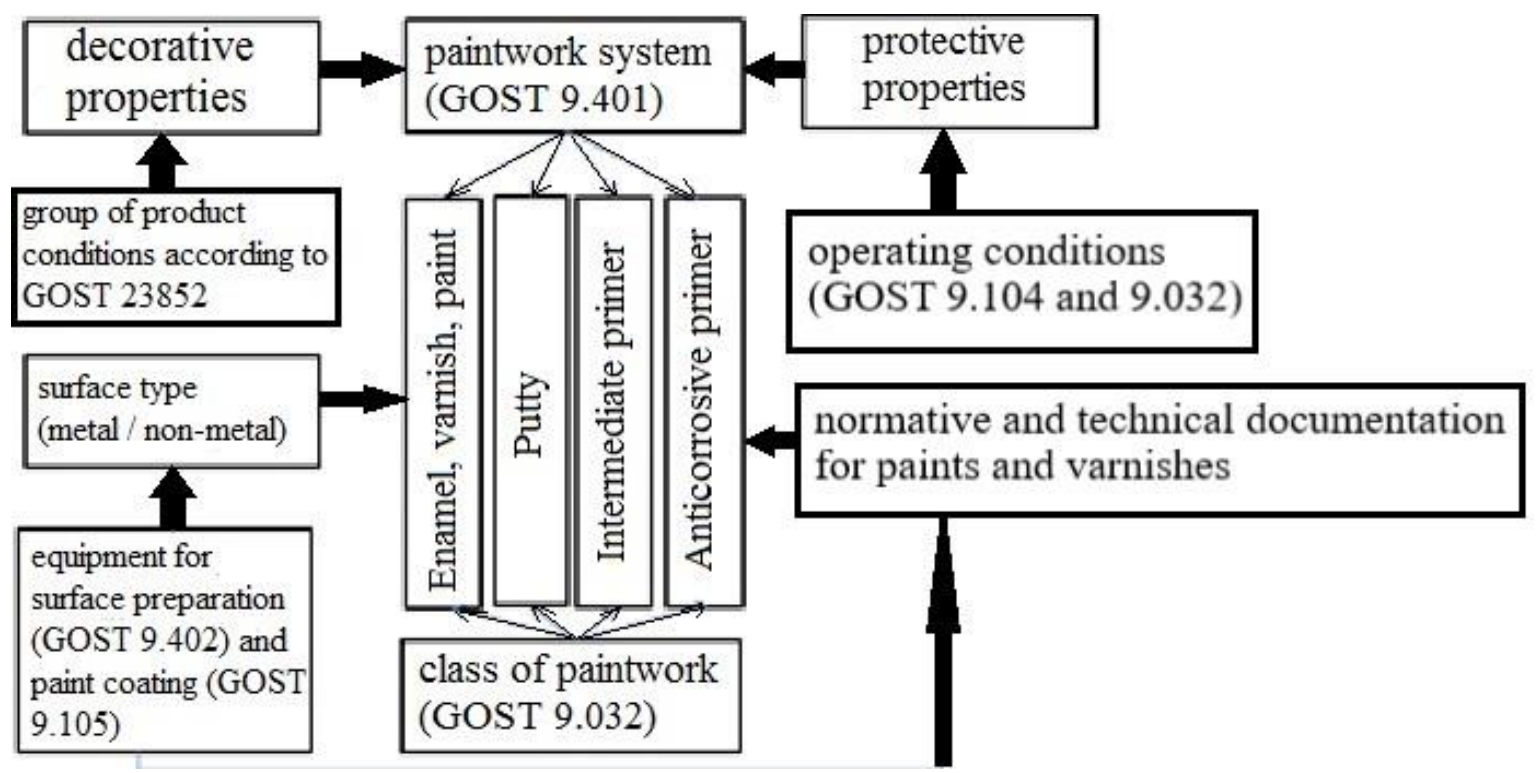

Figure 1 Logical model for choosing paint and varnish coatings in accordance with GOST 9.401

The presented approach allows for a scientifically grounded choice of paint and varnish coatings for metal structures.

\section{THEORETICAL ANALYSIS}

The design of chemical plants for the paint and varnish industry is systemic in nature and includes a number of basic social-organizational and engineering-technological stages. When developing a working project and managing design processes, mathematical modeling, methods for optimizing technological processes and a technical and economic analysis of the design decisions are used [4,5]. The project development process includes a system of design procedures that solve typical tasks, characterized by specific goals and results, initial data and project resources.

The timing and quality of the project depend on the technical and economic efficiency of the enterprise. To do this, in the algorithm for forming a model of a business process, the structure of the organization is considered, and the departments involved in the implementation of the project are determined, and organizational and technical resources that determine the achievement of the goal of the business process are assessed.

Project documentation includes all information about the project being implemented, intended for the customer. In accordance with the Decree of the Government of the Russian Federation of February 16, 2019, No. 87, the "Regulation on the composition of sections of project documentation and requirements for their content" was introduced. The organization of a technological process is a systematic work that requires taking into account all the necessary indicators of the process. When developing a project, you need to be guided by the main documents, since, when drawing up the project documentation, the initial data of the technological project are formed.

The business process of designing a technological line for applying paint and varnish coatings is a sequence of operations, from receiving an order for the development of a painting line to creating a project and subsequent commissioning [6-8]. The process includes organizational and technological procedures, the sequential implementation of which leads to the receipt of a document that has a regulated form of registration, which makes it possible to form a business process using logical and mathematical modeling. 
The technology, organization and management of the chemical-technological system of paint and varnish coatings is drawn up in the form of a regulation, the basic data for which can be obtained using the proposed algorithm.

The algorithm for choosing a paint and varnish technology consists of the following stages:

- $\quad$ assessment of the main criteria for the choice of technology and definition of the variable;

- $\quad$ analysis of existing technologies and selection of suitable technological solutions;

- comparative analysis of technologies;

- $\quad$ choice of technology and determination of its economic efficiency;

- $\quad$ presentation of results (technological regulations).

When using a business process model, alternative solutions should be provided, which will improve the design efficiency in the event of problems in the implementation of the selected design solution and the need to change it [8]. Based on the formation of a technical proposal for the development of a line, technological variables are determined that are included in the object of the business process model [6]. In addition to them, it is necessary to include variables that characterize the design process itself:

- deadlines;

- material design resources;

- $\quad$ the effectiveness of the use of personnel.

The context diagram of the design process is proposed, presented in Figure 2.

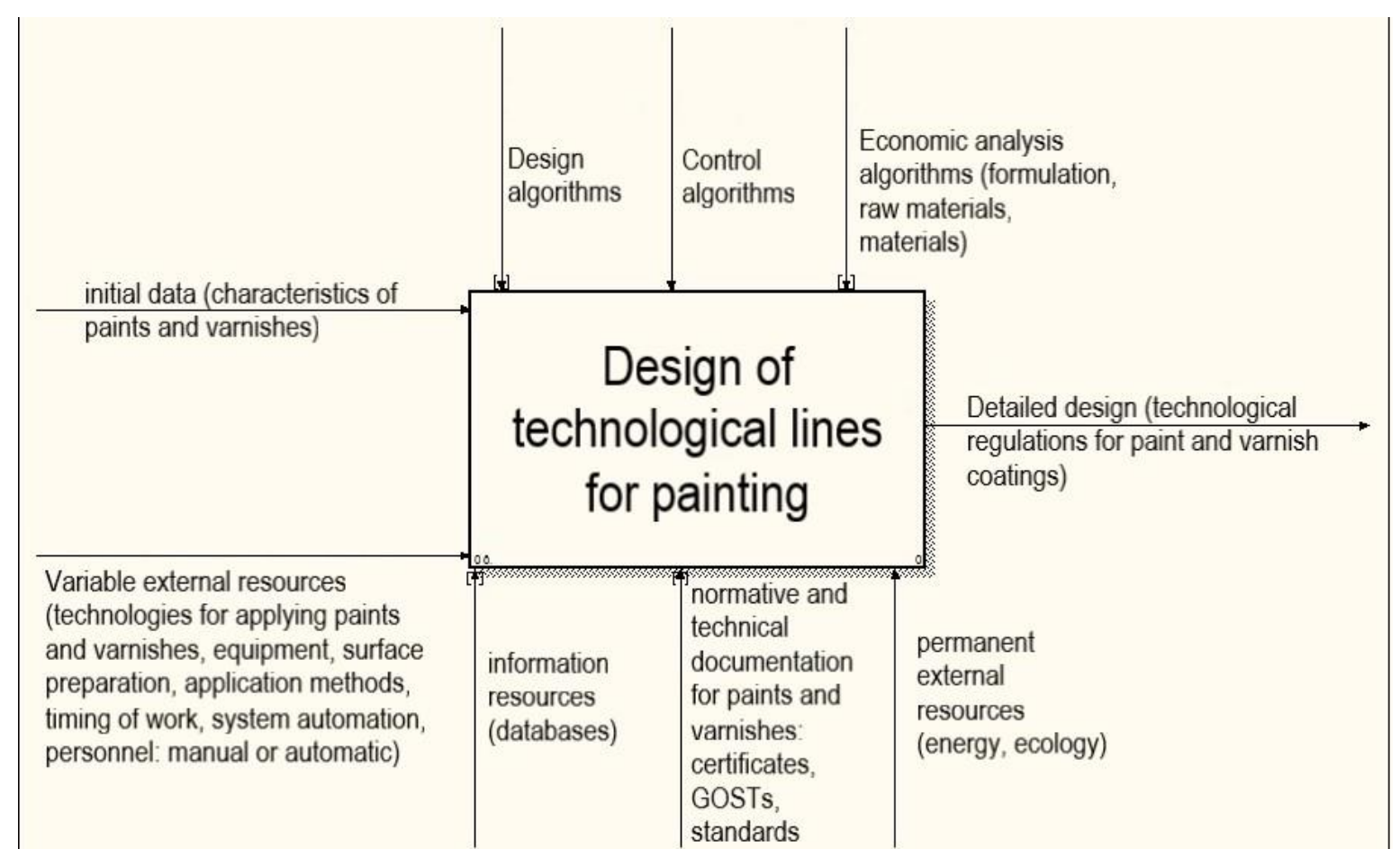

Figure 2 The business process of designing a paint line

The business process of designing a paint line includes the following operations:

- $\quad$ Formation of an array of initial data (characteristics of paints and varnishes).

- Selection and use of external variable resources in relation to the project (technology of applying paints and varnishes, equipment, surface preparation, terms of work, system automation, personnel (manual labor or automation). 
- Technical and economic analysis (formulation of paints and varnishes, raw materials, materials).

- Design algorithm.

To manage the process, three indicators must be considered:

- product indicators (characteristics of paints and varnishes);

- process indicators (information about design resources);

- indicators of customer satisfaction of the project (approved project documentation).

When creating a project, one criterion of the efficiency of the system is selected from these three indicators, the rest of the indicators are used as restrictions, but they are necessarily included in this system.

It is possible to evaluate the project of the painting line by the following results: the costs of design, installation and operation of equipment (approximate economic analysis); quality indicators that meet the requirements of the project; terms of project implementation.

\subsection{Information resources (technology databases)}

The data and logical and mathematical models used in the creation of the technology for dyeing products come from the information base based on the results of queries, which are: obtaining information about paints and varnishes and their manufacturers; selection of paints and varnishes in terms of appearance, operating conditions, durability, physicochemical and physicomechanical properties; selection of a coating system and technology for its production; search for a standard design solution in the project archive.

\subsection{Permanent external resources (energy, ecology)}

Energy resources and environmental requirements, as external resources in the organization of the process, are used as constraints, but they are necessarily included in this system. As restrictions are used such factors as: the location of production, cleaning or processing of raw materials, as well as available to the enterprise energy capacity [9].

\subsection{Regulatory documentation (standards, GOST, certificates)}

The development of a technological project is carried out in accordance with the requirements of legislative and regulatory documents.

\subsection{Technological regulations for coating}

The technological regulations contain a description of the finished product in accordance with the requirements of Russian or international standards and the production technology with a high degree of detailing of production operations, the order of their execution, as well as permissible changes in the main technological parameters and characteristics. The use of the proposed algorithm contributes to the achievement of optimal technical and economic indicators of production and increases the competitiveness of the project being developed.

The business process implementation algorithm consists of three stages:

- development of a technological scheme;

- technique - economic analysis of the scheme;

- technological regulations.

At the first stage of the business process, the choice of painting technology and selection of equipment takes place; to select the technological process for painting the product, it is necessary to determine the coating material [10], the coating system and the sequence of operations of the technological process of painting. When choosing the necessary data, information resources are used in the form of a database. Based on the 
resource analyzes of the design process, standard paint line projects are defined or new ones are created. Choosing a system of paint and varnish coatings, it is necessary to set the operating conditions in accordance with GOST 9.401.

For the selected paintwork system, the material balance is calculated, and the values of all material resources are determined. Based on the results of the stage, a technical task is formed.

At the second stage, the technological solution obtained at the first stage is formed, economic models are calculated, inefficient resources are changed, the fulfillment of technological, organizational and operational restrictions is checked and the final version of the scheme with its indicators is formed. An economic analysis of the line is necessary to assess the effectiveness of the decisions made, including a cost-benefit analysis, the calculation of the cost of modernization and reengineering measures, and an assessment of innovative programs.

The third stage of the design algorithm is implemented only for one technological scheme, as a result of which the sections of the technological regulation are formed, including the characteristics of the technological process.

Returning to the previous stages of the design process is possible to correct technological characteristics in case of inconsistencies in indicators when calculating the material balance or choosing structural elements of equipment, or choosing an alternative technological scheme at the second stage of the algorithm.

It should be noted that the structural analysis of design resources at all stages of project development reduces the likelihood of returning to previous stages, and in case of return, quickly find a way out of the problem due to the availability of alternative design solutions.

The developed algorithm for designing a technological line for applying paint and varnish coatings is used to organize and implement the technological process of painting metal structures, which are operated, including in the arctic climate, allows for an economic analysis of the project and create a technological scheme.

\section{ALGORITHM APPLICATION RESULTS}

The algorithm is actively used by the scientific and design departments, the design bureau, the machinebuilding plant, which are part of the SPA Lakokraspokrytie (Khotkovo).

The algorithm was applied in the implementation of contracts of SPA Lakokraspokrytie on the development of industrial paints and varnishes for painting electric motors and technology for their application. The technology of coloring electric motors allows to unify the technological process of coloring various types of electric motor parts for different climatic versions of the product. The dyeing technology made it possible to organize the dyeing of up to 20 thousand electric motors (or 40 thousand $\mathrm{m} 2$ ) per month on a productive area of $72 \times 18 \mathrm{~m}$ with minimal energy consumption, and ensured the production of high-quality paintwork with a long service life.

\section{CONCLUSION}

The algorithm for designing a technological line for applying paint and varnish coatings, developed by a team of authors, is applied at SPA Lakokraspokrytie. Integration of the algorithm into the design process of new painting booths and reengineering of existing ones allowed the company to significantly increase its income, reduce time and resource costs.

\section{REFERENCES}

[1] MENSHIKOV, V.V., RYBKIN, V.A. The concept of innovative "paint technologies" and its practical implementation. Paints and varnishes and their application. 2016, no. 5, pp. 49-55. 
[2] BOLDYREV, V., MEN'SHIKOV, V., IL'DARKHANOVA, F., PUCHKOVA, V., STRAPOLOVA, D. Harmonization of technical demands to paint coating as a component of competitiveness increase on the international market. In: METAL 2020: 29rd International Conference on Metallurgy and Materials. Brno: TANGER, 2020, pp. 649-654.

[3] NEDASHKOVSKIY, K.I., GULSHIN, A.V., AVERINA, Yu.M., et al. Investigating corrosion resistance of heavy-duty steel fasteners regarding assemblies operating in maritime climates under high pressures. Herald of the Bauman Moscow State Technical University, Series Mechanical Engineering. 2020, no. 1, pp. 94-106.

[4] MEN'SHIKOV, V.V., BOGOMOLOV, B.B., BYKOV, E.D., AVERINA, Yu.M., RYBINA, E.O., KURBATOV, A.Yu. Basics of the design of painting plants. Moscow: D. Mendeleev State Technical University, 2018.

[5] BOGOMOLOV, B.B. Structural modeling of chemical technological processes. Moscow: D. Mendeleev State Technical University, 2016.

[6] BOLDYREV, V.S., AVERINA, Yu.M., MEN'SHIKOV, V.V., KUZNETSOV, S.V., KOLYBANOV, K.Y. Technologicaland organization engineering of paint processing. Theoretical Foundations of Chemical Engineering. 2020, vol. 54, Issue 3, pp. 420-424.

[7] BOGOMOLOV, B., BOLDYREV, V., ELISTRATKINA, V., MEN'SHIKOV, V., SEINA, Ya., ZUBAREV, A. Information-computing system for designing and construction of industrial painting lines. In: Conference Proceedings 22nd International Conference MEKON 2020. 2020, pp. 1-9.

[8] BOGOMOLOV, B.B., BOLDYREV, V.S., ZUBAREV, A.M., MESHALKIN, V.P., MEN'SHIKOV, V.V. Intelligent logical information algorithm for choosing energy- and resource- efficient chemical technology. Theoretical Foundation of Chemical Engineering. 2019, vol. 53, Issue 5, pp. 709-718.

[9] AVERINA, Yu.M., KALYAKINA, G.E., MEN'SHIKOV, V.V. et al. Neutralisation process design for electroplating industry wastewater containing chromium and cyanides. Herald of the Bauman Moscow State Technical University, Series Natural Sciences. 2019, no. 3, pp. 70-80.

[10] BOLDYREV, V.S., MEN'SHIKOV, V.V., SAVINA, A.S., BOGATOV, N.A., ZOTKIN, A.P., IL'DARHANOVA, F. A. RAZVODOVA, A.A. General approaches to improving anticorrosion and antifouring coatings. In: METAL 2020: 29rd International Conference on Metallurgy and Materials. Brno: TANGER, 2020, pp. 702-705. 